điển, kết quả phát hiện cả 4 bệnh nhân đều có đột biến gen CYP21A2. Trong đó, 75\% bệnh nhân (3 trong 4) đều là nam và có kiểu gen p.V281L/p.L307FfsX6. Bênh nhân còn lại là bệnh nhân nữ duy nhất, có kiểu gen: p.P30L + p.P459_L464dup/p.P459_L464dup, đây là một đột biến mới chưa từng được công bố trên bất kỳ cơ sở dữ liệu hay nghiên cứu nào trên thế giới.

Lời cám ơn. Nghiên cứu được thực hiện sự giúp đỡ của các cán bộ của Trung tâm nghiên cứu Gen- Protein, Bộ mổn Nhi, Trường Đại học Y Hà Nội; Khoa Nội tiết-Chuyển hóa- Di truyền, Bệnh viện Nhi Trung ương.

TÀI LIỆ THAM KHẢO

1. Merke D.P. và Bornstein S.R. (2005). Congenital adrenal hyperplasia. The Lancet, 365(9477), 2125-2136.

2. Gonçalves J., Friães A., và Moura L. (2007). Congenital adrenal hyperplasia: focus on the molecular basis of 21-hydroxylase deficiency. Expert Rev Mol Med, 9(11), 1-23.

3. Krone N., Braun A., Roscher A.A. và cộng sự. (2000). Predicting phenotype in steroid 21- hydroxylase deficiency? Comprehensive genotyping in 155 unrelated, well defined patients from southern Germany. J Clin Endocrinol Metab, 85(3), 1059-1065.

4. New M.I. (2003). Inborn errors of adrenal steroidogenesis. Mol Cell Endocrinol, 211(1-2), 75-84.

5. New M.I. (1998). Diagnosis and Management of Congenital Adrenal Hyperplasia. Annu Rev Med, 49(1), 311-328.

6. Speiser P.W. và White P.C. (2003). Congenital Adrenal Hyperplasia. N Engl J Med, 349(8), 776-788.

7. Speiser P.W., Azziz R., Baskin L.S. và cộng sứ. (2010). Congenital Adrenal Hyperplasia Due to Steroid 21-Hydroxylase Deficiency: An Endocrine Society Clinical Practice Guideline. J Clin Endocrinol Metab, 95(9), 4133-4160.

8. New M.I., Abraham M., Gonzalez B. và cộng sứ. (2013). Genotype-phenotype correlation in 1,507 families with congenital adrenal hyperplasia owing to 21-hydroxylase deficiency. Proc Natl Acad Sci U S A, 110(7), 2611-2616.

9. Ogilvie C.M., Crouch N.S., Rumsby G. và cộng sự. (2006). Congenital adrenal hyperplasia in adults: a review of medical, surgical and psychological issues. Clin Endocrinol (Oxf), 64(1), 2-11.

\title{
TÁC DỤNG CỦA CỦA TÂPP YOGA LÊN HUYẾT ÁP VÀ MộT Số CHİ Số NHÂN TRẮC Ở BỆNH NHÂN TĂNG HUYẾT ÁP NGUYÊN PHÁT Độ 1
}

\section{TÓM TẮT}

Điều trị THA bên cạnh dùng các loại thuốc hạ huyết áp thì vấn đề thay đổi lối sống cũng góp phần quan trọng trong việc kiểm soát trị số huyết áp của bệnh nhân. Yoga giúp giảm huyết áp thông qua giảm cắng thẳng, giảm cholesterol máu và tăng độ đàn hồi của thành mach. Để góp phần cung cấp cở sở khoa học cho người bị cao huyết áp kiểm soát thông qua tập luyện Yoga, chúng tôi tiến hành đề tài này. Mục tiệu: (1) Đánh giá tác dụng của tập Yoga trong việc kiểm soát huyết áp ở bệnh nhân tằng huyết áp độ 1 và (2) Đánh giá tác dụng của tập Yoga lên một số chỉ số nhân trắc ở bệnh nhân tăng huyết áp độ I. Đối tượng nghiên cứu: Bệnh nhân THA nguyên phát độ 1 theo tiểu chuẩn chẩn đoán của WHO/ISH 2004, tuổi từ 30 đến 60 tuổi, hiện tại không dùng thuốc điều trị THA và các thuốc ảnh hưởng đến các chỉ số nghiên cứu. Thiết kế nghiên cứu: Nghiên cứu can thiệp có đối chứng. Kết quả: Tập Yoga làm giảm có ý nghĩa thống kê các chỉ số huyểt áp tâm thu và huyết áp tâm

*Đại hoc Y khoa Vinh

**Đai Hoc Vinh

Chịu trách nhiệm chính: Nguyễn Văn Tuấn

Email: tuanminh1976@gmail.com

Ngày nhận bài: 18.2.2021

Ngày phản biên khoa học: 26.3.2021

Ngày duyệt bài: 5.4 .2021
Nguyễn Văn Tuấn*, Hoàng Thị Ái Khuê** trương ở bệnh nhân tăng huyết áp độ 1 so với không tập Yoga. Tập Yoga cũng làm giảm có ý nghĩa thống kề chỉ số BMI, vòng bung và bề dày lớp mõ̃ dưới da ỡ bệnh nhân tăng huyết áp độ 1 so với không tập Yoga.

Tư khóa: Yoga, tăng huyết áp độ 1

\section{SUMMARY}

THE EFFECT OF YOGA ON BLOOD

PRESSURE CONTROL AND SOME ANTHROPOMETRIC INDEXS IN PATIENTS WITH GRADE 1 OF HYPERTENSION

Lifestyle changes are an important issue in treating high blood pressure. Yoga lowers blood pressure by reducing stress, lowering cholesterol and increasing the elasticity of the arteries. We conducted this study to provide a scientific basis for the treatment of hypertension of Yoga. Objectives: (1) Evaluate the effect of Yoga on blood pressure control in patients with grade 1 hypertension and (2) Evaluate the effects of yoga on some anthropometric indexs in patients with grade 1 hypertension. Study subjects: patients with primary grade 1 hypertension according to diagnostic criteria of WHO / ISH 2004, aged 30 to 60 years, currently do not take THA drugs and drugs that affect the study index. Study design: Intervention research. Result: Yoga significantly reduced systolic blood pressure and diastolic blood pressure in patients with grade 1 hypertension compared to non-yoga patients. Yoga also significantly reduced the BMI, 
waist circumference, and subcutaneous fat thickness in patients with grade 1 hypertension compared to non-yoga patients.

Key words: Yoga, level 1 hypertension

\section{I. ĐẶT VẤN ĐỀ}

Tăng huyết áp là yếu tố nguy cơ độc lập đối với các bệnh lý tim mạch. Thậm chí đối với các bệnh nhân tiền tăng huyết áp cũng được coi là tăng nguy cơ bệnh lý tim mạch. Điều trị THA bên cạnh dùng các loại thuốc hạ huyết áp thì vấn đề thay đổi lối sống cũng góp phần quan trọng trong việc kiểm soát trị số huyết áp của bệnh nhân. Yoga đem lại nhiều lợi ích sức khỏe cho người tập như tăng linh hoạt, tăng khả năng tập trung, giải tỏa stress, giảm mõ̃ máu và nhiều lợi ích khác. Y học đã sử dụng Yoga như là một liệu pháp hỗ trợ điều trị bệnh có hiệu quả. Yoga giúp giảm huyết áp thông qua giảm căng thẳng, giảm cholesterol máu và tăng độ đàn hồi của thành mạch. Để góp phần cung cấp cơ sở khoa học cho người bị cao huyết áp kiểm soát thông qua tập luyện Yoga, chúng tôi tiến hành đề tài: "Nghiên cứu tác dụng của luyên tập YOGA trên bệnh nhân tăng huyêt áp độ 1", với 2 mục tiêu:

1. Đánh giá tác dụng của tập Yoga trong việc kiểm soát huyêt áp ở bệnh nhân tăng huyêt áp độ 1 .

2. Đánh giá tác dụng của tập Yoga lên một số chi số nhân trắc ở bệnh nhân tăng huyết áp độ 1.

\section{II. ĐỐI TƯợNG VÀ PHƯƠNG PHÁP NGHIÊN CỨU \\ 1. Đối tượng nghiên cứu}

- Bệnh nhân THA nguyên phát độ 1 theo tiêu chuẩn chẩn đoán của WHO/ISH 2004.

- Tuổi: từ 30 đến 60 tuổi

- Hiện tại không dùng thuốc điều trị THA và các thuốc ảnh hưởng đến các chỉ số nghiên cứu

\section{Phương pháp nghiên cứu}

2.1. Thiêt kếnghiên cứu: Nghiên cứu can thiệp có đối chứng

2.2. Cõ̃ mẫu: Gồm 60 bệnh nhân tăng huyết áp độ 1 được chia làm 2 nhóm:

Nhóm 1: 30 bệnh nhân THA độ 1 tham gia luyện tập YOGA đủ 12 tuần theo chương trình tập Yoga cho người THA tại trung tâm Yoga Ban Mai

Nhóm 2: 30 bệnh nhân THA độ 1 tương đương về độ tuổi, giới tính so với nhóm 1 nhưng không tham gia luyên tập YOGA

2.3. Xử lý số liệu: - Số liệu được xử lý bằng phần mềm SPSS 20.0 .

- Sử dụng ANOVA test để so sánh trung bình các quan sát nếu biến có phân bố chuẩn.

- Sử dụng test X2 để so sánh sự khác biệt về tỷ lệ phần trăm.

\section{KẾT QUẢ NGHIÊN CứU}

1. Hiệu quả giảm tỷ lệ bệnh nhân bị tăng huyết áp tại thời điểm nghiên cứu (t3) so với thời điểm bắt đâu nghiên cứu (to) ỏ nhóm tập Yoga

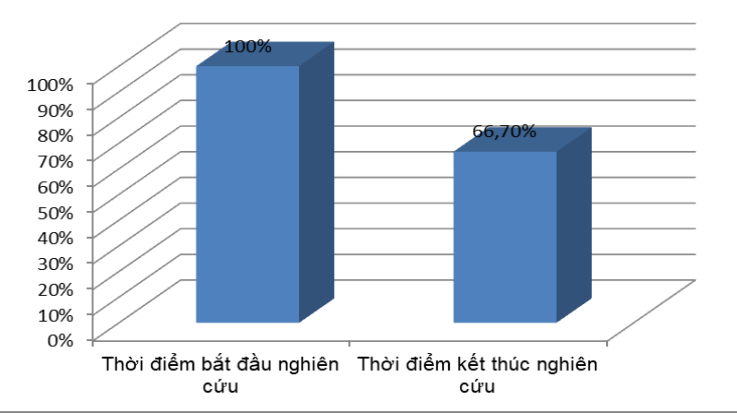

Biểu đồ 1. Tỷ lệ bệnh nhân tăng huyêt áp tại các thời điểm nghiên cứu

Trong nghiên cứu của chúng tôi, tập Yoga có tác dụng kiểm soát huyết áp một cách có ý nghĩa. Sau thời điểm nghiên cứu có 33,3\% bênh nhân có chỉ số huyết áp trở về mức bình thường.

2. Hiệu quả tập Yoga lên chỉ số huyết áp của đối tượng nghiên cứu

Bảng 1. Chỉ số huyêt áp của đôi tượng nghiên cứu ở các thời điểm nghiên cứu

\begin{tabular}{|c|c|c|c|c|c|c|}
\hline \multirow[b]{2}{*}{$\begin{array}{l}\text { Chỉ số nghiên } \\
\text { cứu }\end{array}$} & \multicolumn{3}{|c|}{ Nhóm tâp Yoga } & \multicolumn{3}{|c|}{ Nhóm chứng } \\
\hline & $\begin{array}{l}\text { Thời điểm } \\
\text { bắt đâuu } \\
\text { nghiên cứu }\end{array}$ & $\begin{array}{l}\text { Thời điểm } \\
\text { kết thúc } \\
\text { nghiên cứu }\end{array}$ & $\mathrm{p}$ & $\begin{array}{l}\text { Thời điếm } \\
\text { bắt đâuu } \\
\text { nghiên cứu }\end{array}$ & $\begin{array}{l}\text { Thời điểm } \\
\text { kết thúc } \\
\text { nghiên cứu }\end{array}$ & $\mathrm{p}$ \\
\hline $\begin{array}{l}\text { Huyết áp tâm } \\
\text { thu (mmHg) }\end{array}$ & $\begin{array}{c}152,2 \pm \\
6,4\end{array}$ & $\begin{array}{c}138,1 \pm \\
5,9\end{array}$ & $<0,001$ & $\begin{array}{c}151,5 \pm \\
9,7\end{array}$ & $\begin{array}{c}147,7 \pm \\
8,3 \\
\end{array}$ & 0,2345 \\
\hline $\begin{array}{l}\text { Huyết áp tâm } \\
\text { trương (mmHg) }\end{array}$ & $90,6 \pm 6,2$ & $85,4 \pm 4,5$ & 0,0005 & $89,8 \pm 6,4$ & $87,5 \pm 7,6$ & 0,2099 \\
\hline
\end{tabular}

Tập Yoga làm giảm có ý nghĩa thống kê chỉ số huyết áp tâm thu và huyết áp tâm trương so với nhóm chứng $(p<0,05)$.

\section{Hiệu quả tập Yoga lên các chỉ số nhân trắc của đối tượng nghiên cứu}

Bảng 2. Chỉ sổ BMI, vòng bụng và bề dày lớp mỡ dưới da bụng ở các thời điểm nghiên cứu

\begin{tabular}{|c|c|c|c|c|c|c|}
\hline \multirow{2}{*}{$\begin{array}{c}\text { Chi số nghiên } \\
\text { cứu }\end{array}$} & \multicolumn{3}{|c|}{ Nhóm tập Yoga $(\mathbf{n}=\mathbf{3 0})$} & \multicolumn{3}{c|}{ Nhóm chứng $(\mathbf{n}=\mathbf{3 0})$} \\
\cline { 2 - 7 } & Thời điếm & Thời điếm & $\mathrm{p}$ & Thời điếm & Thời điếm & $\mathrm{p}$ \\
\hline
\end{tabular}




\begin{tabular}{|c|c|c|c|c|c|c|}
\hline & $\begin{array}{c}\text { bătt đâu } \\
\text { nghiên cứu }\end{array}$ & $\begin{array}{c}\text { kết thúc } \\
\text { nghiên cứu }\end{array}$ & & $\begin{array}{c}\text { bắt đầu } \\
\text { nghiên cứu }\end{array}$ & $\begin{array}{c}\text { kết thúc } \\
\text { nghiên cứu }\end{array}$ & \\
\hline BMI $\left(\mathrm{kg} / \mathrm{m}^{2}\right)$ & $23,8 \pm 3,5$ & $22,1 \pm 2,8$ & 0,0422 & $23,5 \pm 2,7$ & $23,7 \pm 2,3$ & 0,9561 \\
\hline Vòng bụng $(\mathrm{cm})$ & $84,5 \pm 6,5$ & $78,7 \pm 4,3$ & 0,0001 & $87,8 \pm 5,4$ & $85,8 \pm 6,4$ & 0,1219 \\
\hline $\begin{array}{c}\text { Lớp mỡ dưới da } \\
\text { bụng }(\mathrm{cm})\end{array}$ & $5,7 \pm 2,3$ & $3,9 \pm 1,3$ & 0,0004 & $6,2 \pm 3,5$ & $6,1 \pm 3,7$ & 0,9147 \\
\hline
\end{tabular}

Tập Yoga làm giảm có ý nghĩa thống kê các chỉ số BMI, vòng bụng và bề dày lớp mỡ dưới da bụng $(p<0,05)$.

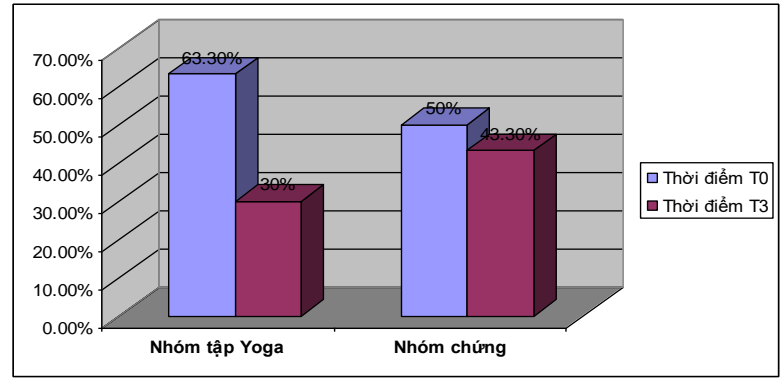

Biểu đồ 1. Tỷ lệ bênh nhân thừa cân ở các thời điểm nghiên cứu của nhóm tập Yoga so với nhóm chứng (TO: thời điểm băt đầu nghiên cúu; T3: Thời điểm kêt thúc nghiên cứu)

Nhóm tập Yoga làm giảm tỷ lệ người có thừa cân từ $63,3 \%$ ở thời điểm trước nghiên cứu xuống còn $30 \%$ ở thời điểm kết thúc luyện tâp Yoga $(p<0,05)$. Ớ nhóm chứng không có sự khác biệt có ý nghĩa thống kê về tỷ lệ người có thừa cân ở thời điểm sau so với trước nghiên cứu $(p>0,05)$.

\section{BÀN LUÂN}

1. Hiệu quả của tập Yoga lên các chỉ số huyết áp. Khi khảo sát một bệnh nhân tăng huyết áp, theo khuyến cáo của Hội tim mạch quốc gia Việt Nam và Hội tăng huyết áp Thế giới năm 2004 (WHO/ISH 2004) cân xác định các chỉ số huyết áp tâm thu, huyết áp tâm trương và chỉ số huyết áp trung bình. Cũng theo WHO/ISH 2004 thì mục tiêu cần đạt của việc điều trị tăng huyết áp là huyết áp tâm thu < $140 \mathrm{mmHg}$ và huyết áp tâm trương $<90 \mathrm{mmHg}$.

Điều trị tăng huyết áp ngoài việc dùng thuốc hạ huyết áp thì việc thay đổi lối sống và tăng cường vận động thể lực, giảm các stress cũng góp phần quan trọng vào việc giảm các chỉ số huyết áp. Theo khuyến cáo của Hội tim mạch quốc gia Việt nam và Hội tăng huyết áp Thế giới năm 2004, đối với tăng huyết áp nguyên phát giai đoạn 1 khi chưa có tổn thương cơ quan đích thì có thể chưa cần phải dùng thuốc điều trị mà việc điêu trị ở giai đoạn này là tích cực thay đổi lối sống và hạn chế các yếu yếu tố nguy cơ.

Các nhà nghiên cứu khoa học về tim mạch đã cho thấy rằng: chỉ cần hạ được $5 \mathrm{mmHg}$ ở người cao huyết áp là số tai biến mạch máu não giảm được 35-40\%. Nhiều tác giả khi nghiên cứu tác

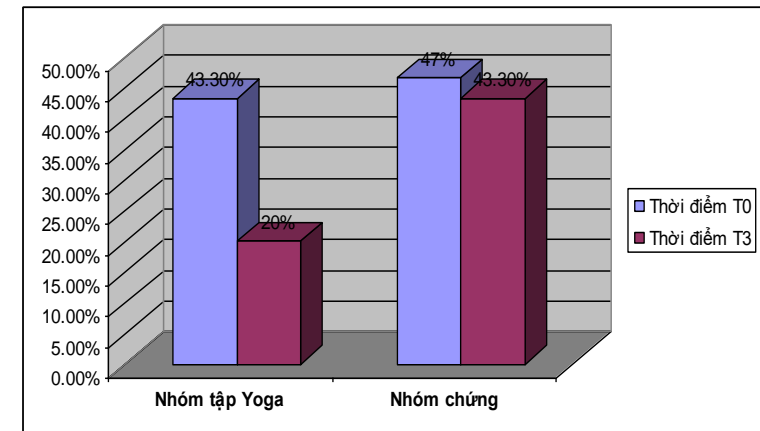

Biểu đồ 2. Tỷ lệ bệnh nhân béo bụng ở các thời điểm nghiên cứu của nhóm tập Yoga so với nhóm chứng (TO: thời điểm bắt đằu nghiên cứu;

T3: Thời điểm kêt thúc nghiên cứu)

Nhóm tập Yoga làm giảm có ý nghĩa thống kê tỷ lệ người có béo bụng ở thời điểm sau kêtt thúc nghiên cứu so với thời điểm bắt đầu nghiên cứu $(p<0,05)$.

động của Yoga đã đưa ra nhận định rằng: Yoga là phương pháp thể dục khá hoàn hảo giúp phòng, hỗ trợ điêu trị bệnh cao huyết áp có hiệu quả.

Với đặc điểm bài Yoga gồm thực hiện các asana (tư thế), với kỹ thuật điều khiển hơi thở (pranayama) và Thiền định (dhyana). Yoga đem lại nhiều lợi ích sức khỏe cho người tập như tăng linh hoạt, tăng khả năng tập trung, giải tỏa stress, giảm mõ̃ máu và nhiêu lợi ích khác. Chính vì vậy mà hiện nay Yoga có mặt ở nhiều nước trên thế giới. Ở các nước phát triển, Yoga không những được tổ chức tại các trung tâm thể dục mà còn mă̆t ở nhiều bênh viên. $Y$ học đã sử dụng Yoga như là một liệu pháp hỗ trợ điều trị bệnh có hiệu quả.

Yoga có hàng ngàn tư thế khác nhau, khi thực hiên mỗi tư thế đều có sự kéo giãn hoăc chèn ép cớ, tập trung tâm trí khi thực hành các asana và pranayama để cảm nhận hởi thở, cảm nhân sự căng cơ, kéo giãn dây chằng đồng thời tập trung một điểm và nhìn một điểm khi thực hành các tư thế giúp kết nối tâm - thân. Mặt khác, Yoga có tác dụng tăng lượng oxy trong máu, điều hoà thần kinh thực vật, cân bằng giao cảm và phó giao cảm, giảm huyết áp. Thư giãn trong Yoga bằng cách thiền định, nâng cao sức 
khoẻ, tăng độ linh hoạt, giải toả stress và giảm sự căng cơ. Khi giảm thừa cân béo phì cũng đồng nghĩa với giảm được huyết áp. Căng thẳng là yếu tố nguy cơ chính của tăng huyết áp, pranayama và thiên định là phương pháp hạ huyết áp và có thể chữa được cao huyết áp, chỉ cân thiền định 15- 20 phút một lần, ngày 2 lần là có thể chữa được cao huyết áp [5].

Lợi ích đâu tiên của Yoga là trái tim. Yoga từ lâu đã được biết đến để giảm huyết áp và làm chậm nhịp tim. Một nhịp tim chậm hơn có lợi cho những người huyểt áp cao, bệnh tim và đột quy, Yoga có liên quan với giảm cholesterol và mức độ chất béo trung tính cũng như tăng cường chức năng hê thống miễn dịch.

Nghiên cứu của Hoàng Thi Ái Khuê, Pham Thi Hằng Nga (2011) về tác dụng của tập Yoga trên bệnh nhân đái tháo đường typ 2 cho thấy tập Yoga có tác dụng làm giảm tần số tim, giảm có ý nghĩa các chỉ số huyết áp tâm thu và huyết áp tâm trương ở bệnh nhân đái tháo đường typ 2 [1].

Về hiệu quả của tập Yoga lên chỉ số huyết áp ở bệnh nhân tăng huyết áp độ 1 trong nghiên cứu của chúng tôi cho thây ở nhóm tâp Yoga chỉ số huyết áp tâm thu ở thời điểm kết thúc nghiên cứu là $138,1 \pm 5,9 \mathrm{mmHg}$ thấp hơn có ý nghĩa thống kê so với thời điểm bắt đầu nghiêu cứu là $152,2 \pm 6,4 \mathrm{mmHg}$ với $p<0,01$ (bảng 1), chỉ số huyết áp tâm trương ở thời điểm kết thúc nghiên cứu cũng thấp hơn so với thời điểm bắt đầu nghiên cứu, sự khác biệt không có ý nghĩa thống kê $(p<0,05)$. Còn ở nhóm chứng kết quả ở bảng 1 cho thấy chỉ số huyết áp tâm thu và tâm trương ở thời điểm kết thúc nghiên cứu không khác biêt có ý nghĩa thống kê so với thời điểm bắt đầu nghiên cứu.

Hagins M, States R, Selfe T và cs (2013) phân tích gộp 17 nghiên cứu về vai trò của tập Yoga lên chỉ số huyết áp ở bệnh nhân tăng huyết áp cho thấy tập Yoga làm giảm có ý nghĩa chỉ số huyết áp tâm thu $(-4,17[-6,35,-1,99], p=$ $0,0002)$ và chỉ số huyết áp tâm trương $(-3,62$ [$4,92,1,6], p=0,0001)$. Và các tác giả kết luâan rằng cần khuyến cáo tập Yoga như là liệu pháp đâu tiên cho bệnh nhân tăng huyết áp để kiểm soát chỉ số huyết áp bên cạnh các phương pháp điều trị khác [5].

2. Hiệu quả tập Yoga lên các chỉ số nhân trắc của đối tượng nghiên cứu. Yoga là môn khoa học có tác dụng tăng cường sức khoẻ, phòng và chữa bệnh có hiệu quả. Yoga bao gồm các tư thế (asana), kỹ thuật điều khiển hơi thở (pranayama), tập trung tâm trí (dhyana) và cảm nhận; trong đó, hô hấp (pranayama) là linh hồn của yoga. Chính vì vây, một giờ thực hành Yoga bẳng một giờ tập thể dục, cộng với một giờ tập thở và một giờ tập trung tâm trí. Yoga gồm khoảng 8.000 tư thế và 8 kỹ thuâtt thở. Khi thực hành các asana thường xuyên có sự căng kéo cơ, năng lượng tiêu hao tương đối nhiều và thường xuyên có sự thay đổi hoặc kết hợp giữa hô hấp bằng ngực trên, ngực dưới và hô hấp bằng bụng (hô hấp bằng cớ hoành). Đă̆c điểm của hô hấp trong Yoga thường chậm, điều hoà và sâu nên đem được nhiều oxy vào đồng thời đào thải nhiều khí cacbonic. Tế bào đủ oxy và quá trình cung cấp năng lượng được diễn ra theo hệ oxy hoá đường và mỡ làm giảm lipid máu và tiểu hao lipid tữ các mô mõ, từ đó cân nặng được giảm đi rõ rêt. Bên cạnh đó, khi tập luyện Yoga, luôn sự kết hợp giữa "tâm và thân" dần dần sẽ giúp người tập ý thức từng cử chỉ, hành động của chính mình và có được sự bình an trong mọi hoạt động, phát triển khả năng tập trung, định tâm và trí tuệ, thần kinh cân bằng, ăn uống điều độ cũng là nguyên nhân gây giảm cân, giảm chỉ số BMI, vòng bụng và vòng mông.

Những nghiên cứu mới đây đã chỉ ra rằng: Yoga không những ngăn ngừa tăng cân mà còn giúp người tập giảm một trọng lượng đáng kể. Đàn ông và phụ nữ ở lứa tuổi 50 trở lên thường là lứa tuổi điển hình có trọng lượng cơ thể tăng nhanh dần theo mỗi năm, khi sinh lực cơ thể dân suy giảm mà lại không giảm được lượng calo tiêu thụ. Nghiên cứu đầu tiên đã cho thấy hiệu quả của Yoga trong việc giảm cân và cũng có thể tăng cân nếu muốn. Trong nghiên cứu, các nhà khoa học đã tiến hành thử nghiệm tác động của Yoga trong viêc thay đổi trong lượng cơ thể với 15550 người ở lứa tuổi $53-57$. Kết quả như sau: Những người nam giới và phụ nữ có trọng lượng cân bình thường nếu luyện tập Yoga thường xuyên (ít nhất 30 phút mỗi tuần) trong vòng từ 4 đến 5 năm chỉ tăng có $1,5 \mathrm{~kg}$ ít hơn hẳn so với những người không tập Yoga (tăng 4,5 kg tới $6 \mathrm{~kg}$ ). Những người nam giới và phụ nữ có trọng lượng lớn, nếu luyện tập Yoga thường xuyên sẽ giảm được 2,5kg, còn những người không luyện tập Yoga sẽ tiếp tục tăng tới $6 \mathrm{~kg}$. Các nhà nghiển cứu cho biết hiệu quả của Yoga với việc giảm cân và duy trì trong lượng. "Trong quá trình luyện tập Yoga, cơ thể đốt cháy đủ lượng calo để giảm cân, nhưng hầu hết lại có rất ít người luyên tập Yoga". Giáo sư Alan D.Kristal, ĐH Washington nói "Từ kinh nghiệm của tôi, tôi nghĩ Yoga là cách tốt nhất giúp mọi người hiểu rõ về cơ thể của mình. Vì thế khi ăn đủ lượng thức ăn, chúng ta có thể cảm nhận được lượng thức ăn tiêu thụ vào cơ thể 
đã quá đầy, điều đó có thể giúp chúng ta dễ dàng ngừng ăn trước khi ăn quá nhiều". Theo kết quả nghiên cứu của Dhananjai $S$, Sadashiiv và cộng sự (2013) về hiêu quả của tập Yoga ở bênh nhân béo phì cho thây tập Yoga có tác dụng làm giảm lo lắng, giảm trầm cảm và giảm cân nặng ở bệnh nhân béo phì [4].

Kết quả nghiên cứu của chúng tôi ở bảng 2 cho thấy; ở nhóm tập Yoga cải thiện có ý nghĩa các chỉ số nhân trắc liên qua đến tình trạng béo phì thừa cân là chỉ số BMI, số đo vòng bụng và bề dày lớp mõ dưới da bụng đều giảm có ý nghĩa thống kê sau thời điểm 3 tháng tập Yoga $(p<0,05)$. Kết quả nghiên cứu ở biểu đồ 1 và 2 cũng cho thấy; tập Yoga có tác dụng làm giảm có ý nghĩa thống kê tỷ lệ người tăng huyết áp độ 1 có thừa cân và béo bụng so với nhóm chứng. Ở nhóm tập Yoga, tại thời điểm bắt đầu nghiên cứu tỷ lê người bị thừa cân là $63,3 \%$ và sau thời gian tập Yoga tỷ lệ này giảm xuống còn $30 \%$. Tương tự, tập Yoga có tác dụng làm giảm có ý nghĩa tỷ lệ bệnh nhân béo bụng. Tại thời điểm bắt đầu nghiên cứu tỷ lệ bệnh nhân có béo bụng ở nhóm tập Yoga là $43,3 \%$ và sau thời gian tập Yoga tỷ lệ này giảm xuống còn $20 \%$ khác biệt có ý nghĩa thống kê so với nhóm chứng (biểu đồ 2).

\section{KẾT LUÂ̂N}

- Tập Yoga làm giảm có ý nghĩa thống kê các chỉ số huyết áp tâm thu và huyết áp tâm trương ở bệnh nhân tăng huyết áp độ 1 .

- Tập Yoga cũng làm giảm có ý nghĩa thống kê chỉ số BMI, vòng bụng và bề dày lớp mõ dưới da ở bệnh nhân tăng huyết áp độ 1 .

\section{TÀI LIÊU THAM KHẢO}

1. Phạm Thị Hằng $\mathrm{Nga}$, Hoàng Thị Ái Khuê (2011), Tác dụng của tập Yoga lên một số chỉ tiêu hình thái, sinh lý, sinh hóa ở bệnh nhân đái tháo đường tại thành phố Vinh, Luận văn thạc sỹ sinh họ.

2. Bhavanani $A B$, Madanmohan, and $Z$, Sanjay (2014), "Immediate cardiovascular effects of pranava pranayama in hypertensive patients", Indian J Physiol Parmacol. 12, pp. 125-129.

3. Caffrey $R, P$, Ruknui, and U, Hatthakit (2005), "The effects of Yoga on hypertensive persons in Thailand", Holistic Nursing Practice. 19(4), pp. 173-180.

4. Dhananjai $S$, Sadashiv, and $S$, Tiwari (2013), "Reducing psychological distress and obesity through Yoga practice", Int J Yoga. 12, pp. 213-216.

5. Hagin $M, R$, State, and Selfe (2016), "Effectiveness of Yoga for hypertension: systematic review and meta-analysis", Evid Based Complement Alternat Med.

6. Khatri D, KC, Mathur, and S, Gahlot (2017), "Effects of yoga and mediatation on clinical and biochemical parameters of metabolic syndrome", Diabetes Resercher and Clinical Practice. 78(3), pp. 9-10.

7. Mizuno J and HL, Monterio (2015), "An assessment of sequence of Yoga excercise to patients with arterial hypertension", Jounal of bodywork and movement thẻapies. 17, pp. 35-41.

8. Rajbhoj, Pratibha Hemant, Shete, Sanjay Uddhav, and Verma, Anita (2015), "Effect of Yoga Module on Pro-Inflammatory and AntiInflammatory Cytokines in Industrial Workers of Lonavla: A Randomized Controlled Trial", J Clin Diagn Res. 9(2), pp. 1-5.

\section{BIẾN ĐổI SÓNG ALPHA TRÊN ĐIỆN NÃO BỆNH NHÂN TÂM THẦN PHÂN LIẸTT}

\section{TÓM TẮT}

Mục tiêu: Tìm hiểu đặc điểm năng lượng, biên độ và tân số của sóng alpha trên điện não đố ở bệnh nhân tâm thần phân liệt. Phương pháp nghiên cứu: Phân tích về chỉ số năng lượng, tần số và biên độ của sóng alpha trên 100 bệnh nhẩn tâm thân phân liệt được điểu trị tại Khoa Tâm thân, Bệnh viện Quân y 103 và so sánh với ở 100 người trưởng thành khỏe mạnh. Kết quả nghiên cứu: Năng lượng và biên độ sóng alpha ở nhóm bệnh thấp hơn có ý nghĩa thống kê so với ở nhóm chứng ở hầu hết các kênh ghi ở hai

${ }^{1}$ Bệnh viện Quân y 103

Chịu trách nhiệm chính: Đinh Việt Hùng

Email: bshunga6@gmail.com

Ngày nhận bài: 23.2.2021

Ngày phản biên khoa học: 26.3.2021

Ngày duyệt bài: 5.4.2021
Đinh Việt Hùng1, Nguyễn Văn Linh ${ }^{1}$ giai đoạn nhắm mắt và giai đoạn tăng thông khí. Trong khi đó tần số sóng alpha khổng có sự biên đổi ở bệnh nhân tâm thần phân liệt so với nhóm chứng. Kết luận: Kết quả nghiên cứu này đưa ra bằng chứng về sự biến đổi sóng alpha trên điện não ở bệnh nhân tâm thần phân liệt.

Tư khóa: Tẩm thần phân liệt, năng lượng, biên độ, tần số, sóng alpha.

\section{SUMMARY}

\section{CHANGES OF ALPHA WAVES IN \\ ELECTROENCEPHALOGRAMS OF SCHIZOPHRENIA PATIENTS}

Objectives: Investigate the energy characteristics, amplitude and frequency of alpha waves from electroencephalography recordings in schizophrenia patients. Methods: Analysis of energy index, frequency and amplitude of alpha waves in 100 